\title{
Engineered Cementitious Composites Using High Volume Fly Ash and PVA Fibers for the Sustainable Development in Construction Industry
}

\author{
Srinivasa C. $\mathrm{H}^{1}$, Venkatesh ${ }^{2}$ \\ ${ }^{1}$ Assistant Professor, Department of Civil Engineering, Government Engineering College, Kushalnagar, \\ Coorg District, India. Email: chs.mysore@gmail.com \\ ${ }^{2}$ Principal, Government Engineering College, Kushalnagar Coorg District, India.
}

\begin{abstract}
For each ton of Cement produced, one ton of $\mathrm{CO}_{2}$, a greenhouse gas, is released into the atmosphere. Worldwide, the Cement industry produced about 1.4 billion tons in 1995, which caused the emission of as much $\mathrm{CO}_{2}$ gas as 300 million automobiles. Our industry has a responsibility and societal duty to make a contribution towards taking the steps necessary to achieve sustainable development. A scientific approach towards conserving natural resources involves increasing durability of structures, because more durable structures need to be replaced less frequently. Such increased durability can be achieved by choosing appropriate mix designs and selecting suitable Aggregates and admixtures. Development of Engineered Cementitious Composite (ECC) materials using High volume of Fly Ash and Polyvinyl Alcohol (PVA) fibers will produce the most promising construction materials with High durability. This Paper focuses on Development and study of Engineered Cementitious Composites using High Volume Fly Ash and Polyvinyl Alcohol Fiber, the use of which will increase the durability and hence lead to the Sustainable Development in Construction Industry.
\end{abstract}

Keywords: Engineered Cementitious Composites Fly Ash, Polyvinyl Alcohol Fiber Superplasticizer. Sustainable Development.

\section{INTRODUCTION}

Majority of the countries are putting sincere efforts to correct the results of the past disregard in utilizing the natural resources in connection with the growing infrastructural needs of the world. Infrastructural development should take place with due consideration to protect the mother earth by conserving the natural resources. The manufacturing of Portland Cement, which is the commonly used binder for Concrete mixtures, also requires large amount of natural materials. It is one of the most energy intensive and polluting industries. There is a rapidly increasing concern that we can no longer continue to ignore the pollution problems on the one hand and the unrestricted depletion of natural resources on the other hand. A satisfactory solution is essential because, if unresolved, environmental pollution and depletion of natural resources present a clear threat to our standard and quality of living.

The immense pressure on the world's environment means that measures must be taken today to safeguard natural resources for tomorrow. This is the challenge that the construction industry has to face. Research by international environmental organizations like the World Wildlife Fund for Nature (WWF) suggest that humans are using natural resources at a rate of $25-$ $50 \%$ greater than the planet can replenish them.
WWF suggests that we should cut our consumption by two thirds. However, cutting down our use of natural resources does not mean we need lower our standard of living; we just need to use natural resources more wisely.

Concrete is the most accepted construction material in the field of Infrastructural Development on our Mother Earth with more than 11.4 billion tons of Concrete consumed annually worldwide. It was estimated that each ton of Cement produced generates an equal amount of Carbon Dioxide, a major contributor for Green House Effect and Global Warming. Ordinary Portland Cement, though costly and energy intensive is the most widely used ingredient in the production of Concrete mixes. Unfortunately, production of Cement itself involves emission of large amounts of Carbon Dioxide into the atmosphere. Hence, it is inevitable either to search for another material or partly replace it by an alternate material. Any such material which can be used as an alternate or as a supplementary to Portland Cement would lead to a sustainable construction. ECC with High Volume Fly Ash along with PVA fibers has recently gaining popularity as an efficient, durable and sustainable option for a variety of Concrete applications.

Civil and Structural Engineers who have developed High-Strength Concrete structures over 
the last few decades have given hopes for stronger structures. However, there is also increasing recognition that when a certain level of compressive Strength is reached, the failure of the structure will be dominated by brittle fracture in tension. This recognition has lead to an expansion of materials property development towards tensile ductility in recent years.

\section{LITERATURE SURVEY}

Concrete is the important construction materials used worldwide. Historically, structural designers have primarily relied on Concrete to carry compressive loads. However, in real field conditions, Concrete is also subjected to tensile Stresses due to loading and environmental effects including shrinkage, chemical attacks and thermal effects. [1]

High-Strength Concrete performs well under pure compression loading. However, many structures experience Flexural and shear loading that invariably introduce tensile Stresses into the material. In dynamic loading, compressive Stress waves travelling through the thickness of a Concrete element and approaching a free surface would reflect back as a tensile wave that results in High velocity debris ejected on the back side of the structure. No amount of steel reinforcement can prevent this type of failure mode involving Concrete spalling and fragmentation since the reinforcement always require a Concrete cover. [2]

The corrosion of reinforcing bars is one of the main causes of early deterioration of Concrete structures and reduction in the service life of the structures. Recent life-cycle analyses indicate that substantial material resource consumption, primary energy use and $\mathrm{CO}_{2}$ emission occur during the service life of bridge due to repeated maintenance. Reduced corrosion induced damage is expected to contribute to the development of sustainable infrastructure system. [3]

While explaining the motivations for developing Bendable Concrete, Li reveals, it was a response to many of the major concerns we face every day in the Society. The things like climate change, infrastructure is experiencing more and more loads from extreme weather conditions. The concerns about environmental sustainability is utmost important in reducing Carbon Dioxide emissions of producing Cement.

Compared with Normal Concrete, ECC uses more Cement due to the absence of Coarse Aggregate in the mixture design. High Cement content usually introduces higher hydration heat, autogenous shrinkage and cost. Moreover, the associated increase in primary energy and emission of Carbon Dioxide create a negative environmental impact. A plausible solution would be to replace a large portion of Cement in ECC by industrial byproducts. For example, coal combustion products (Fly Ash), without sacrificing the mechanical properties in general and tensile ductility in particular. [4]

ECC represents a special kind of High performance fiber reinforced cementitious composite featuring High tensile ductility. Unlike Concrete and conventional fiber-reinforced Concrete (FRC) which shows unloading after matrix first cracking, ECC exhibits tensile-strain hardening behaviour achieved by sequential development of matrix multiple cracking. The tensile ductility of ECC is several hundred times that of Normal Concrete and crack width in ECC is self controlled and reaches a constant value $(\sim 60 \mu \mathrm{m})$ after $1 \%$ elongation. It has been reported that ECC has lower water permeability and lower effective chloride diffusivity in the presence of micro-cracks when compared with cracked Concrete in which the crack width is not self controlled and is usually in the range of several hundred micrometer to several millimeter. [5]

The High content of Cement in ECC is a consequence of Rheology Control for easy fiber dispersion and, more essentially, matrix toughness control for strain hardening behaviour. To achieve strain hardening matrix fracture toughness has to be limited such that the multiple cracking could occur before reaching maximum fiber bridging Stress. Large Aggregates are hence eliminated in the mixture, resulting in High Cement content compared with Normal Concrete. [6]

The Bendable Concrete has a compressive Strength similar to that of Conventional Concrete. But while Conventional Concrete has a strain capacity of $0.01 \%$, ECC has a tensile Strength capacity of 3 to $5 \%$, or about 300 to 500 times as much, making it far more ductile. ECC therefore acts more like a ductile metal than a brittle glass, leading to a wide variety of applications [7].

If durability and eventually sustainability are important, current construction practices and codes of practice must undergo a paradigm shift to achieve Concrete structures that have tight cracks or are crack-free in preference to High Strength [8].

One of the remarkable characteristics of PVA fiber is strong bonding with Cement matrix. A layer of $\mathrm{Ca}(\mathrm{OH})_{2}$ is formed round the PVA fibers. It is assumed that $\mathrm{Ca}^{+}$and $\mathrm{OH}^{-}$ions in Cement slurry are attracted by PVA fibers and makes $\mathrm{Ca}(\mathrm{OH})_{2}$ layer. It seems reasonable to think that $\mathrm{Ca}(\mathrm{OH})_{2}$ layer plays important role for bonding Strength [9].

The Characteristic Deformability Factor test is used to quantify the effects of particle size distribution of the fine Aggregates in ECC as outlined by Kong et.al. A standard Concrete slump 
cone is filled with fresh ECC and discharged onto a level Plexiglas or glass plate. Following discharge, two orthogonal diameters of the ECC "pancake" are averaged and a Characteristic Deformability Factor, denoted by $\tau$ is calculated using $\tau=\frac{D_{1}-D_{0}}{D_{0}}$

Where, $D_{1}$ is the average of two orthogonal "pancake" diameters, in $\mathrm{mm}$ and $\mathrm{D}_{0}$ is the diameter of bottom of original slump cone, in mm. [10]

\section{METHODOLOGY}

In the world of Materials Engineering, raw ingredients are shaped into a composite material through processing. Traditionally, selection of raw ingredients is based on empiricism. In recent years, composite materials are systematically being designed. One such material is "Engineered Cementitious Composite" (ECC). Micromechanics can be a powerful tool to deliberately tailor the composite ingredients, such as fiber dimensions and surface coatings along with sand particle amount and size. In addition, knowledge of material processing and its effect on both fresh and hardened properties aid in composite design.

The Methodology has been divided in to three phases. The first Phase covers the development of ECC mixes. Second phase covers the study of fresh properties of developed mixes in the laboratory. The third phase highlights the study of hardened properties of developed mixes in the laboratory.

Mix the Cement, Fly Ash and fine Aggregate until the mixture is thoroughly blended and is of uniform color. Add 75 percent of water and 75 of percent of Superplasticizer and mix it thoroughly until the Concrete appears to be homogeneous. Add slowly the remaining water and Superplasticizer mix it and then add PVA fibers. All the constituents are meticulously mixed until the desired homogeneity and consistency is achieved.

\section{INGREDIENTS OF ENGINEERED CEMENTITIOUS COMPOSITES}

Bendable Concrete or ECC resembles regular Concrete but can weigh up to $40 \%$ less, consisting mostly of the same ingredients except for the Coarse Aggregates. It has small Polyvinyl Alcohol (PVA) fibers embedded within it, $8 \mathrm{~mm}$ long and about 39 microns in diameter, about half the thickness of a human hair. They have a nanometer-thick surface coating that allows them to slip rather than break under heavy loads. In place of Coarse Aggregates, it relies on fine sand as Coarse Aggregates disturb placement of the fibers and destroy the ductility.
1. Cement: The Cement used was UltraTech 53 Grade Ordinary Portland Cement. The specific Gravity of Cement is equal to 3.15 with Initial Setting Time of 55 minutes.

2. Fine Aggregates: $4.75 \mathrm{~mm}$ down locally available Sand was used conforming to IS 3831970 which has a Specific Gravity of 2.69.

3. Fly Ash: Fly Ash used was Class F and brought from Raichur Thermal Power Station (RTPS). It has a Calcium Oxide content of 6.29\%.

4. Superplasticizer: Polycarboxylic Ether (PCE) based High Performance Superplasticizer was used. It has a Relative Density of $1.08 \mathrm{gm} / \mathrm{cc}$

5. Polyvinyl Alcohol Fibers: Ultra-High Performance Fibers were used with Aspect Ratio equal to 210 and Tensile Strength of $1400 \mathrm{MPa}$.

6. Water: Water which is fit for drinking was used.

\section{PROPORTIONING OF CONCRETE}

The specific or recommended guidelines are not available for the Engineered Cementitious Composites Mix Design. Hence, the Ideal Mix Proportion given in the Literature of ECC-Concrete was used in this study. Various Mix Proportions were tried keeping the Water to Binder ratio as Constant and varying the dosages of Superplasticizer. Table 1 show the ideal mix proportion used in this study. Table 2 shows notation.

\begin{tabular}{|c|c|c|c|c|c|c|c|c|}
\hline \multicolumn{9}{|c|}{ Mix Proportion } \\
\hline 要: & 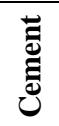 & $\begin{array}{l}\bar{E} \\
\text { E్ }\end{array}$ & $\begin{array}{l}\frac{\pi}{0} \\
\frac{3}{2} \\
\frac{2}{x}\end{array}$ & के & $\dot{\Phi}^{m}$ & $\begin{array}{l}\Delta^{\circ} \\
\dot{\bar{d}} \\
\dot{8}\end{array}$ & $\sum_{x}$ & 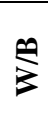 \\
\hline 草 & $\underset{8}{8}$ & $\begin{array}{l}\stackrel{\infty}{\circ} \\
0\end{array}$ & กิ & $\underset{+}{\sigma}$ & $\begin{array}{l}8 \\
\infty \\
\infty \\
m\end{array}$ & $\stackrel{8}{\circ}$ & 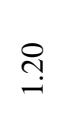 & तิ \\
\hline
\end{tabular}

Table 1. Mix Proportion of ECC

\begin{tabular}{|l|l|}
\hline Symbol & Definition \\
\hline SP & Superplasticizer \\
\hline FA/PC & Fly Ash to Portland Cement Ratio \\
\hline W/B & Water to Binder Ratio \\
\hline PVA-0.0 & Percentage of PVA Fiber $=0.0 \%$ \\
\hline
\end{tabular}

Table 2. Notation

VI. CASTING

$15 \mathrm{~cm}$ cubes were used for the purpose of determining the Compressive Strength of the various specimens. Cylindrical moulds of $15 \mathrm{~cm}$ diameter and length $30 \mathrm{~cm}$ were used for the purpose of determining the Split Tensile Strength. 
For investigating Flexural Strength, moulds of $50 \mathrm{~cm} \times 10 \mathrm{~cm} \times 10 \mathrm{~cm}$ were used. Curing and testing procedures were followed as per Indian Standards.

\section{TESTING OF ENGINEERED CEMENTITIOUS COMPOSITES}

To evaluate the fresh properties, tests such as Slump flow Test (T50 cm flow test) and Characteristic Deformability Factor $(\Gamma)$ test have been carried out. Further, hardened properties were also studied to know the behaviour of the Specimens in Compression, Indirect Tension and Bending.

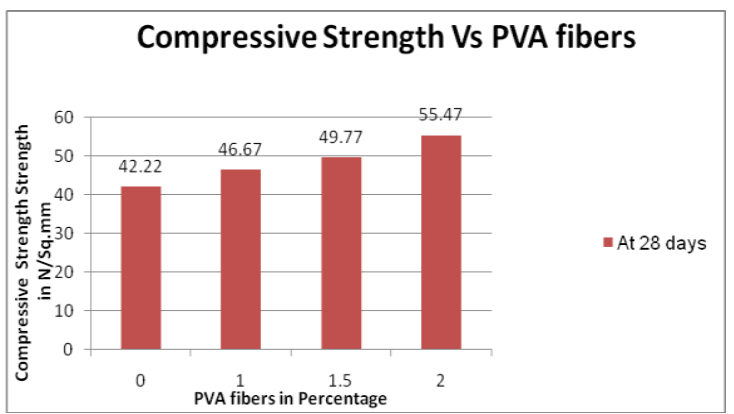

Fig 1. Compressive Stress Graph

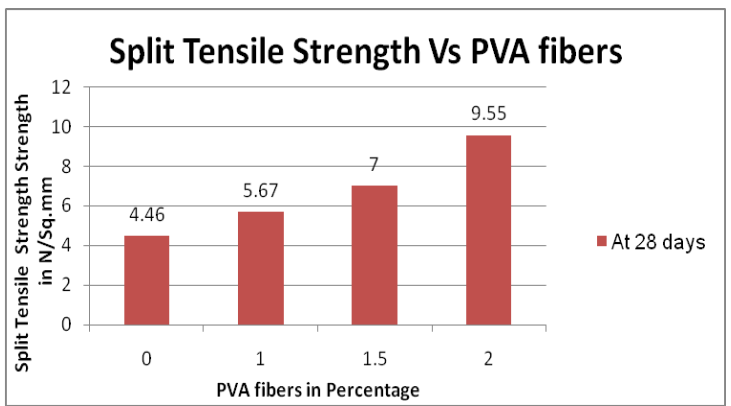

Fig 2. Split Tensile Stress Graph

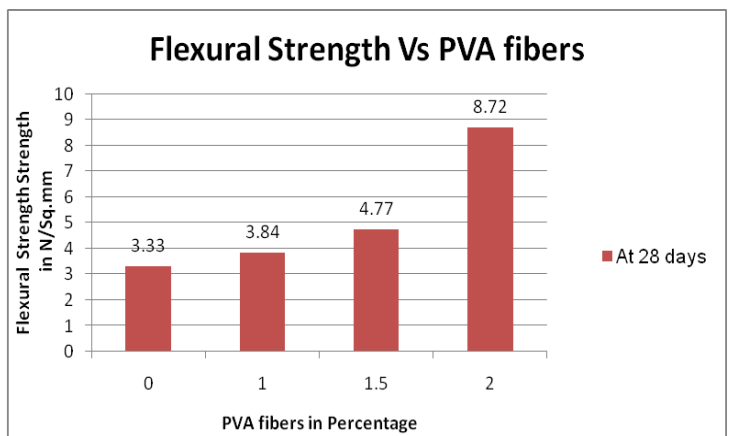

Fig 3. Flexural Stress Graph

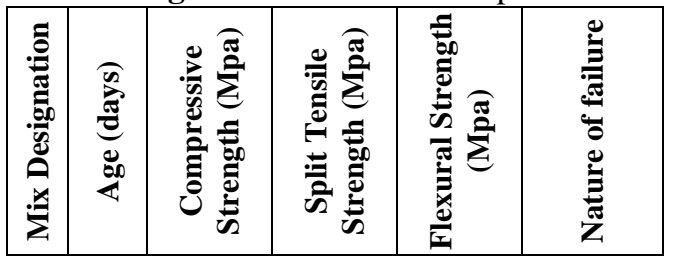

\begin{tabular}{|c|c|c|c|c|c|}
\hline$\stackrel{0}{\circ}$ & 28 & 42.22 & 4.46 & 3.33 & Brittle \\
\hline & 28 & 46.67 & 5.67 & 3.84 & Ductile \\
\hline 吕 & 28 & 49.77 & 7.00 & 4.77 & Ductile \\
\hline 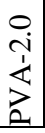 & 28 & 55.47 & 9.55 & 8.72 & Ductile \\
\hline
\end{tabular}

Table 3. Hardened properties of the Engineered Cementitious Composites

\section{RESULT AND CONCLUSION}

Figures 1, 2 and 3 represent the Compressive Stress, Split Tensile Stress and Flexural Stress Graphs respectively. Hardened properties are shown in Table 3. A Compressive Strength of 55.47 Mpa, corresponding Split Tensile Strength of $9.55 \mathrm{Mpa}$ and Flexural Strength of 8.72 have been obtained for a fiber volume of $2 \%$ at 28 days age, which gives Split Tensile Strength of $17.216 \%$ of its Compressive Strength compared to only $10 \%$ in case of Normal Concrete. The Flexural Strength has been increased from3.33 MPa to 8.72 $\mathrm{MPa}$. The experimental investigations show that the Composite has a considerable amount of increase in tensile Strength. The increased Tensile Strength significantly minimizes the tensile cracks and prevents the ingress of harmful chemical responsible for corrosion. The Research Work suggests the need for an alternative material as far as Strength and Durability are concerned.

\section{SCOPE FOR FUTURE WORK}

The Strain hardening behaviour of the Concrete can be known by conducting the Uniaxial Tensile tests on Concrete specimens using Universal Testing Material (UTM). The development of micro-cracks can also be analysed using Environmental Scanning Electronic Microscope (ESEM).

\section{ACKNOWLEDGEMENT}

The Author would like to graciously thank Mr. Shatrughna Thimmappa, Columbus, Indiana, USA who has taken a lot of personal interest in procuring the indispensable PVA fibers for the Research Work. The Research work was carried out with the assistance from Raichur Thermal Power Station (RTPS), Raichur, India.

\section{REFERENCES}


[1]. Mustafa Sahmaran et.al. (2009), "Assessing the durability of engineered Cementitious composites under freezing and thawing cycles," Journal of ASTM International, Vol. 6, No. 7, Paper ID JAI102406. Pp. 1-12.

[2]. Victor C. Li. and winter (2011) University of Michigan. "High ductility Concrete for resilient infrastructures," Journal of advanced and High performance materials, pp.16-21.

[3]. Mustafa Sahmaran et.al. (2008), "Corrosion Resistance Performance of Steel -Reinforced ECC Beams." ACI Materials Journal / May-June 2008. Pp. 243-250

[4]. En Hua Yang. et.al. (2007) "Use of High volume Fly Ash to improve ECC Mechanical Properties and Material Greenness," ACI Materials Journal/November-December 2007. pp. 303-311

[5]. En-Hua Yang et.al. (2008), "Fiberbridging constitutive law of engineered Cementitious composites," Journal of advanced Concrete technology Vol. 6, No. 1, pp.181-193.

[6]. Shuxin Wang and Victor C. Li. (2007) "Engineered Cementitious composites with High-Volume Fly Ash," ACI Materials Journal/May-June 2007. pp. 233-241

[7]. En-Hua Yang et.al. (2008) "Fiber bridging constitutive law of engineered Cementitious composites," Journal of advanced Concrete technology Vol. 6. No. 1, pp. 181-193.

[8]. Mustafa Sahmaran et.al. (2010), "Engineered Cementitious Composites. Can composites be accepted as crack-free Concrete?" Transportation Research Record: Journal of the Transportation Research Board, No. 2164, Transportation Research Board of the National Academics, Washington D.C., DOI: 10.3141/2164-01. pp. 1-8.

[9]. Dr. A W Dhawale, Mrs. V P Joshi, "Engineered Cementitious Composites for Structural Applications." International Journal of Application or Innovation in Engineering \& Management. Vol 2, Issue 4, April 2013. pp. 198-205

[10]. Michael D. Lepech et.al. (2008) "Design of Green Engineered Cementitious Composites for improved Sustainability," ACI Materials Journal / NovemberDecember 2008. pp. 567-575 